OPEN ACCESS

Edited by:

Anwen Shao,

Zhejiang University, China

Reviewed by:

Andrew David Greenhalgh,

The University of Manchester

United Kingdom

Yaohui Tang,

Shanghai Jiao Tong University, China

${ }^{*}$ Correspondence:

Gilberto Ka-Kit Leung

gilberto@hku.hk

Specialty section:

This article was submitted to

Cellular Neuropathology,

a section of the journal

Frontiers in Cellular Neuroscience

Received: 19 November 2021

Accepted: 10 January 2022

Published: 14 February 2022

Citation:

Liu J, Zhu Z and Leung GK-K

(2022) Erythrophagocytosis by

Microglia/Macrophage in Intracerebral Hemorrhage: From Mechanisms

to Translation.

Front. Cell. Neurosci. 16:818602.

doi: 10.3389/fncel.2022.818602

\section{Erythrophagocytosis by Microglia/Macrophage in Intracerebral Hemorrhage: From Mechanisms to Translation}

\author{
Jiaxin Liu', Zhiyuan Zhu' ${ }^{1,2,3}$ and Gilberto Ka-Kit Leung ${ }^{1 *}$ \\ ' Department of Surgery, LKS Faculty of Medicine, The University of Hong Kong, Queen Mary Hospital, Hong Kong, Hong \\ Kong SAR, China, ${ }^{2}$ Department of Functional Neurosurgery, The National Key Clinical Specialty, The Engineering Technology \\ Research Center of Education Ministry of China, Guangdong Provincial Key Laboratory on Brain Function Repair \\ and Regeneration, The Neurosurgery Institute of Guangdong Province, Guangzhou, China, ${ }^{3}$ Zhujiang Hospital, Southern \\ Medical University, Guangzhou, China
}

Intracerebral hemorrhage $(\mathrm{ICH})$ is a devastating condition characterized by hematoma related mass effect. Microglia/macrophage $(\mathrm{M} \varphi)$ are rapidly recruited in order to remove the red blood cells through erythrophagocytosis. Efficient erythrophagocytosis can detoxify hemolytic products and facilitate neurological recovery after $\mathrm{ICH}$. The underlying mechanisms include modulation of inflammatory response and oxidative stress, among others. It is a dynamic process mediated by a cascade of signal transduction, including "find-me" signals, "eat-me" signals and a set of phagocytotic receptors-ligand pairs that may be exploited as therapeutic targets. This review summarizes mechanistic signaling pathways of erythrophagocytosis and highlights the potential of harnessing M $\varphi$-mediated phagocytosis for $\mathrm{ICH}$ treatment.

Keywords: erythrophagocytosis, efferocytosis, macrophage, microglia, intracerebral hemorrhage, hematoma, phagocytosis

\section{INTRODUCTION}

In intracerebral hemorrhage (ICH), the rupture of brain vessels results in the accumulation of millions of red blood cells (RBCs) within brain parenchyma. Surgical excavation of hematoma is not recommended for most ICH cases due to questionable clinical benefits and adverse effects of surgery (Hemphill et al., 2015). Hemolysis within the hematoma may cause significant secondary injuries and irreversible neurological deficits due to the toxic properties of hemolytic products (Ziai, 2013). Microglia and monocyte-derived macrophage ( $\mathrm{M} \varphi)$ are rapidly recruited at the bleeding site and may aid hematoma resolution by phagocytosing RBCs through erythrophagocytosis (Zhao et al., 2009; Chang C. F. et al., 2018; Jing et al., 2019). This detoxication process helps alleviate the brain injuries results from secondary detrimental process such as neuroinflammation and oxidative stress. Increasing number of studies have investigated the mechanistic signaling and beneficial effects of erythrophagocytosis in ICH (Chang C. F. et al., 2018; Chang et al., 2020; Xu et al., 2020). However, this endogenous erythrophagocytosis tends to be incomplete, and hemolytic productstriggered brain damage remains common and detrimental to recovery after ICH. Thus, enhancing endogenous erythrophagocytosis is an important strategy for ICH treatment.

In this review, we highlight the therapeutic values of targeting erythrophagocytosis in ICH. Firstly, we introduce the neurotoxicity of hematoma and the role of $M \varphi$-mediated 
erythrophagocytosis in hematoma clearance and ICH recovery. Then, we describe the dynamic process of phagocytosis, focusing on the essential membrane receptors in M $\varphi$. We further depict how erythrophagocytosis may be modulated by microenvironmental factors, including inflammatory cytokines and oxidative stress. Finally, we summarize the critical nuclear factors regulating erythrophagocytosis that could serve as druggable targets. The aim is to inform future pre-clinical and clinical studies on accelerating hematoma resolution as a means of improving patient outcomes in ICH.

\section{NEUROTOXICITY OF HEMATOMA}

The extravasated blood plays a critical role in ICH pathology. In acute ICH, the blood cells and other blood components from the ruptured vessels rapidly accumulate in the brain parenchymal, forming a hematoma with mass effect that can destroy the cerebral architecture (mass effect) (Xi et al., 2006). Subsequently, hemolysis occurs, releasing neurotoxic degradation products (hemoglobin, heme, and iron). These substances could cause detrimental effects on brain tissue (Figure 1; Wagner et al., 1996; Nakamura et al., 2005; Xue and Yong, 2020):

- Inflammation is represented by the rapid recruitment of immune cells and the inflammatory cytokines in perihematomal regions (Loftspring et al., 2009; Zia et al., 2012). The hemolysis products, especially hemoglobin and heme, may function as the ligands of Toll-like receptor 4 (TLR-4), which could activate proinflammatory $\mathrm{M} \varphi$ and elevate the levels of proinflammatory cytokines (Figueiredo et al., 2007; Kwon et al., 2015; Lan et al., 2017).

- Oxidative stress is featured by the accumulation of reactive oxygen species (ROS), which oxidize DNA, protein, and lipid, causing tissue damage (Marnett et al., 2003). Iron, generated from the heme degradation, can catalyze the well-studied Haber-Weiss reaction, yielding overwhelming ROS and resulting in oxidative stress (Wu et al., 2003; Nakamura et al., 2005).

- Edema develops as early as hours and peaks at a range of 10-20 days in patients after ICH (Xi et al., 2006). At the early phase ( $<3$ days), thrombin and serum proteins extruded from the hematoma are the leading cause of edema. At the later stage ( $>3$ days), the hemolysis products precipitate delayed edema (Wagner et al., 1996; Urday et al., 2015). Of note, the TLR-dependent inflammation by hemoglobin and heme, as well as the Matrix metallopeptidase 9 (MMP-9) activation and the oxidative stress by iron, could compromise blood-brain barrier integrity and aggravate edema (Katsu et al., 2010; Urday et al., 2015).

Post-ICH hematoma expansion and rebleeding occur commonly in patients, suggesting a continuous enlargement of blood burden within the brain (Brott et al., 1997; Morgenstern et al., 2001). To counteract it, erythrophagocytosis by $\mathrm{M} \varphi$ occurs at both the edge and the center of hematoma, resulting in hematoma reduction (Cao et al., 2016). Timely clearance of hematoma can maintain homeostasis in cerebrovascular units and allows neurological recovery after ICH (Zhao et al., 2009). As such, shrinking hematoma via boosting the endogenous removal of RBCs, the source of hemolysis, has attracted increasing scientific interest in the past decade.

\section{MACROPHAGE/MICROGLIA: THE MAJOR CELL PERFORMING ERYTHROPHAGOCYTOSIS}

At onset, ICH rapidly recruits microglia, neutrophil, monocytes, and T lymphocytes, successively (Xue and Yong, 2020). For hematoma clearance, microglia and monocyte-derived macrophage are 'professional' phagocytes uptaking the damaged cells, including RBCs, in ICH (Xu et al., 2020; Li Q. et al., 2021). Though some 'non-professional' cells, such as endothelial cells, are also involved in erythrophagocytosis in cerebral microbleeds, their roles in ICH remain unknown (Chang R. et al., 2018). Microglia are the brain resident macrophages, mediating diverse functions critical to brain development and injury, such as synaptic pruning and phagocytosis (Paolicelli et al., 2011). For macrophage, their precursor cells - monocyte - are thought to enter the brain as a component of blood at ICH onset while later migrate into the brain via cell adhesion pathways (Engelhardt, 2008; Mracsko et al., 2014). These peripheral monocytes might undergo in situ differentiation into mature macrophages in the ischemic brain (Gliem et al., 2012; Miro-Mur et al., 2016). Interestingly, a recent study found that skull and vertebral bone marrow also supplied monocytes, which infiltrated the brain border (e.g., the dura matter) and developed into macrophages in inflamed brains (Cugurra et al., 2021). Given the limited evidence on ICH, a review on the dynamic infiltration of monocytederived macrophage in the ischemic brain might shed light on future studies (Han et al., 2020). Moreover, perihematomal M $\varphi$ might follow the route of an available scaffold - white matter fibers - and migrate into the hematoma core, aiding the hematoma clearance (Chen et al., 2021). In addition to the white matter, molecules from the scar tissue are also considered able to support $\mathrm{M} \varphi$ activity, including phagocytosis, in brain injuries (Rolls et al., 2009).

Notwithstanding the diverse functions of macrophage and microglia observed in other types of strokes, most ICH studies could not distinguish macrophage from microglia due to the obstacles in differentiating between the two cell types in vivo (Zarruk et al., 2018). Fortunately, with the help of more specific cell markers (e.g., Tmem119 for microglia) and multichannel flow cytometry (Bennett et al., 2016; Li et al., 2018), some researchers had begun to study the two cell types separately in ICH (Chang C. F. et al., 2018; Li Q. et al., 2021). Due to the inconsistent gating strategy applied by these two studies, it remains inconclusive as to how the role of macrophage differs from that of microglia. Therefore, in this review, we use $M \varphi$ to denote the two cell types except when discussing studies that clearly distinguish between the two. Figure 2 summarizes the key findings on erythrophagocytosis after ICH. 


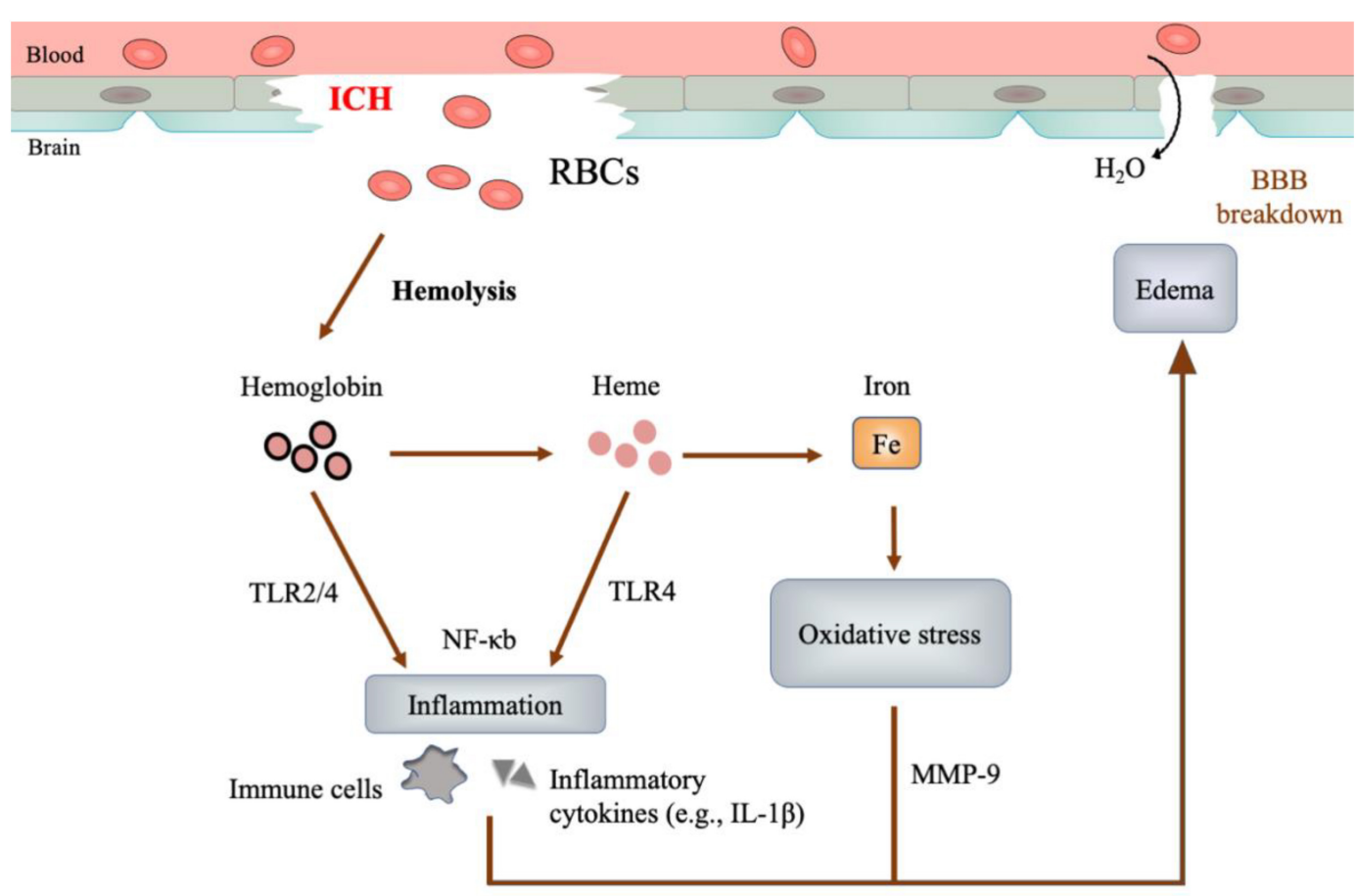

FIGURE 1 | Neurotoxicity of hematoma. After ICH, red blood cells (RBCs) would undergo hemolysis and degrade into hemoglobin, heme and iron consequently. These hemolysis products mediate cascades of inflammation, oxidative stress, and perihematomal edema, causing detrimental injury to the brain.

\section{MEMBRANE RECEPTORS INITIATE ERYTHROPHAGOCYTOSIS}

Exogenous stimulus, such as inflammation, could impair erythrocytes integrity and predispose them to become apoptosislike cells (Lang et al., 2014). The apoptotic erythrocytes are then recognized and phagocytosed by $M \varphi$, a process termed efferocytosis (Trahtemberg and Mevorach, 2017). Erythrophagocytosis in $\mathrm{ICH}$ is a type of efferocytosis. Blocking the $\mathrm{M} \varphi$ receptors for recognizing the apoptotic markers can impair the erythrophagocytosis and impede hematoma resolution. Efficient efferocytosis is important for tissue homeostasis by reducing exposure to toxic components of hemolysis and self-antigens which can substantially induce tissue damage and autoimmune response (Sisirak et al., 2016; Herzog et al., 2019). In ICH, efficient efferocytosis leads to controlled clearance of damaged erythrocyte before injuries are inflicted by uncontrolled hemolysis (Chang C. F. et al., 2018).

As a type of efferocytosis, erythrophagocytosis is a highly orchestrated process which can be separated into four consecutive steps (Hochreiter-Hufford and Ravichandran, 2013; Doran et al., 2020):

(1) sensing: dying cells release "find-me" signals to attract phagocytes;

(2) recognition: aged or abnormal erythrocytes (apoptotic erythrocytes) externalize the "eat-me" signals, such as phosphatidylserine (PtdSer) (de Back et al., 2014; Klei et al., 2017); phagocytes upregulate specific surface receptors (e.g., CD36 and TAM family) to recognize the "eatme" signal on the dying cells; interestingly, apoptotic erythrocytes also express the "don't eat me" signal, CD47, repelling M $\varphi$ from efferocytosis (Ni et al., 2016); Table 1 summarizes the phagocytosis-related receptors by RBCs.

(3) ingestion: phagocytes initiate cytoskeleton rearrangement to facilitate internalization of the dying cells;

(4) digestion and response phase: phagocytes process the corpses and produce anti-inflammatory mediators to suppress inflammatory response.

Of note, the current literature on erythrophagocytosis mainly focuses on the Step 3; the other steps remained largely unexplored in the context of ICH. Current studies have shown the therapeutic value of targeting the "don's eat me signal" from erythrocytes (CD47) and the surface phagocytosis receptors from $\mathrm{M} \varphi(\mathrm{CD} 36$ and TAM family).

\section{CD47}

$\mathrm{CD} 47$ is an integrin-associated transmembrane protein ubiquitously expressed in many cell types including erythrocytes (Olsson et al., 2006). It regulates immune cell infiltration, phagocytosis, and the production of proinflammatory mediators and trophic factors by interacting with integrins and extracellular ligands (Brown and Frazier, 2001; Zhang et al., 2015). For phagocytosis, CD47 on erythrocytes acts as a "don't eat me" signal to block phagocytosis by binding to signal regulatory protein $\alpha(\operatorname{SIRP} \alpha)$ on macrophage (de Back et al., 2014). Preclinical studies have demonstrated the role and therapeutic 

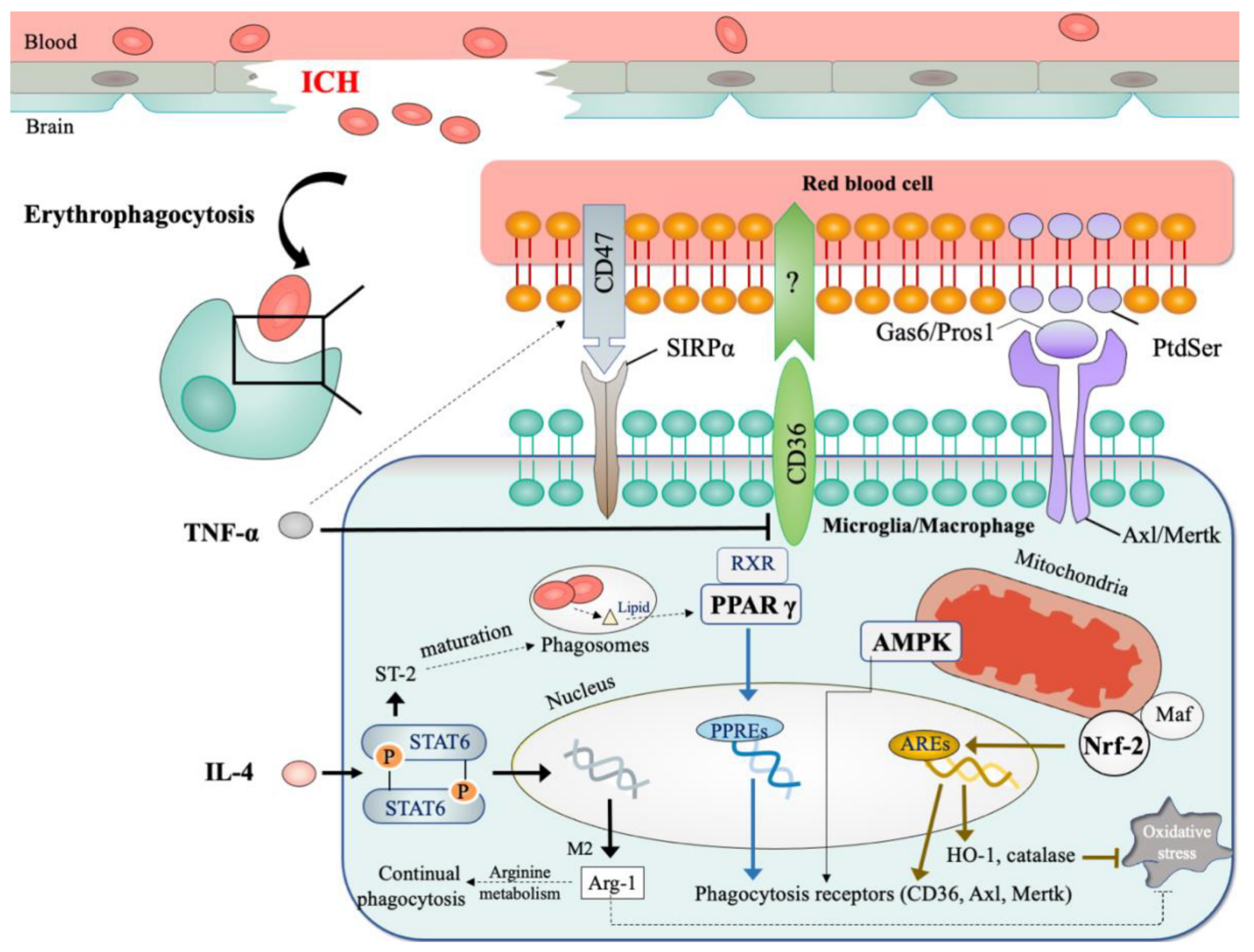

FIGURE 2 | Mechanisms of erythrophagocytosis in ICH. (1) Signals for recognition include: CD47 on erythrocytes serves as the inhibitory signal for erythrophagocytosis; CD36, Axl, and Mertk on phagocytes act as scavenger receptors for clearing erythrocytes. (2) Microenvironment factors (inflammatory cytokines and oxidative stress) shape the phagocytosis by $\mathrm{M} \varphi$. (3) The critical modulators for phagocytosis include PPAR $\gamma$, Nrf2, AMPK. ${ }^{\star}$ The dotted lines showed results from other diseases models.

value of $\mathrm{CD} 47$ in ICH. The perihematomal level of CD47 increases within hours but decreases subsequently, accompanied by $\mathrm{M} \varphi$ infiltration and erythrophagocytosis (Zhou X. et al., 2014; Cao et al., 2016). This explains the reverse correlation between $\mathrm{CD} 47$ and $\mathrm{M} \varphi$-mediated immune response. Intracranial

TABLE 1 | Receptors on the rede blood cells for erythrophagocytosis.

\begin{tabular}{lcl}
\hline Function & Receptors & References \\
\hline "Don't eat-me" signal & CD47 & ICH: Ni et al., 2016; Jing et al., \\
& & 2019; Tao et al., 2020 \\
& Other diseases: Oldenborg, \\
& & 2004 \\
"Eat-me" signal & Phosphatidylserine & ICH: Chang C. F. et al., 2018 \\
& (PtdSer) & Other diseases: Boas et al., \\
& 1998; Sun et al., 2021 \\
& Band 3 clustering & Other diseases: Klei et al., 2017 \\
& Calreticulin & Other diseases: Gardai et al., \\
& 2005; Nilsson et al., 2012
\end{tabular}

injection of CD47 knock-out blood resulted in quicker hematoma resolution and milder brain edema (Ni et al., 2016). This effect was reduced by intracranial injection of clodronate liposomes, a specific phagocytes depletion drug. In all, CD47 may serve as an inhibitory signal in $\mathrm{M} \varphi$-mediated hematoma resolution. Inspiringly, CD47 blocking antibody significantly enhanced hematoma removal after $\mathrm{ICH}$, rendering $\mathrm{CD} 47$ a promising and draggable target in ICH treatment (Jing et al., 2019; Tao et al., 2020).

\section{CD36}

Upon activation by "eat-me" signals, macrophage upregulates several membrane scavenger receptors to direct the ingestion process, including CD36 (Silverstein and Febbraio, 2009). The upregulated precursor intracellular CD36 undergoes glycosylation in the endoplasmic reticulum, followed by transportation to the cell membrane (Alessio et al., 1996; Roszer, 2017). Membrane CD36 cooperates with the $\alpha \mathrm{v} \beta 3$ receptor to engage with the eat-me signal thrombospondin (TSP) on 
apoptotic cells, inducing the internalization and digestion of target cells (Savill et al., 1990, 1992).

In ICH, CD36-mediated apoptotic cells clearance is essential for hematoma resolution. Its transcription was upregulated in the erythrocytes-treated microglia culture as well as the perihematomal region after ICH (Zhao et al., 2007b). Both genetic deletion and antibody blocking of CD36 impeded the phagocytosis of erythrocytes by microglia (Zhao et al., 2007b; Fang et al., 2014). As M $\varphi$-mediated removal of erythrocytes is required for clot clearance, the roles and therapeutic values of CD36 in hematoma development has attracted considerable attention. For example, CD36 knock-out mice was found to have slower hematoma resolution and aggravated deficits when compared to wild-type mice after ICH (Fang et al., 2014). What's more, the same study also found that patients with CD36 deficiency showed impaired hematoma resolution and poorer clinical outcome. Consistently, the upregulation of CD36 generates faster speed of erythrophagocytosis and hematoma resolution (Zhao et al., 2007b; Flores et al., 2016; Wang Y. et al., 2018). Enhancing the upstream regulatory mechanism of CD36, including peroxisome proliferator-activated receptor $\gamma(\operatorname{PPAR} \gamma)$ and the nuclear factor erythroid 2-related factor 2 (Nrf2), is a potential approach to promoting CD36-mediated hematoma clearance.

\section{Axl/Mertk}

TAM - namely, Tyro3, Axl and Mertk - is a group of receptor tyrosine kinases functioning as macrophage scavenger receptor (Lemke and Burstyn-Cohen, 2010). Tyro3 is more highly expressed on neuron rather than on $M \varphi$ in the brain, whereas Axl and Mertk are more abundant on $\mathrm{M} \varphi$ which makes them more relevant to erythrophagocytosis in $\mathrm{ICH}$ (Fourgeaud et al., 2016; Chang C. F. et al., 2018). Axl and Mertk participate in cell survival, migration, and phagocytosis by engaging with the ligands, growth arrest specific 6 (Gas6) and protein s (Pros1) (Shafit-Zagardo et al., 2018). Gas6/Pros1 acts by bridging Axl/Mertk with the "eat-me" signal (PtdSer) on apoptotic cells, initiating the phagocytosis process (Tondo et al., 2019).

In $\mathrm{ICH}, \mathrm{Axl}$, and Mertk might be required for erythrophagocytosis. In a murine model, the transcriptional level of Axl, Mertk and Gas6 ligand are increased within $24 \mathrm{~h}$ after ICH (Tong et al., 2017); deficiency of Axl/Mertk resulted in defective erythrophagocytosis by macrophage in ICH (Chang C. F. et al., 2018). However, results from double knockout Axl/Mertk were inconclusive as to whether both or either of them was responsible for these findings, it is likely that Mertk and Axl may have diversified functions, with Mertk playing important roles in homeostasis and Axl being more involved in inflammatory conditions (Zagorska et al., 2014). Further studies are necessary to define whether Axl or Mertk alone is indispensable for the removal of erythrocytes in ICH. Interestingly, Axl/Mertk also modulates $\mathrm{M} \varphi$ phenotypes and alleviates neuroinflammation in addition to its effects in phagocytosis. In ICH, Toll-like receptors (TLRs) polarizes $\mathrm{M} \varphi$ toward proinflammatory phenotype (M1), as opposed to anti-inflammatory (M2) phenotype (Lan et al., 2017). Axl/Mertk can activate the TLRs suppressors, SOC1 and SOC3, thereby inhibiting M1-like $M \varphi$ activation and suppressing inflammatory response in a range of disease including in ICH (Rothlin et al., 2007; Tong et al., 2017; Chang C. F. et al., 2018; Wu et al., 2021).

From a therapeutic standpoint, exogenous ligands (e.g., recombinant Gas6) can be used to target Axl/Mertk-mediated beneficial effects. In inflammatory conditions, Axl/Mertk is prone to be cleaved from the cell membrane, generating the soluble but unfunctional Axl/Mertk (sAxl/sMertk). sAxl/sMertk competitively occupies the endogenous ligands (Gas6 and Pros1), resulting in the lack of ligands for regulating homeostasis in inflammatory conditions (Cai et al., 2016; Chang C. F. et al., 2018). Therefore, exogenous ligands, such as recombined Gas6 can compensate this insufficiency, serving as the druggable target in augmenting the effects of TAM (Di Stasi et al., 2020). For example, recombined Gas6 promoted inflammation resolution via Axl-dependent manner in experimental ICH (Tong et al., 2017). However, whether the exogenous ligands could facilitate the Axl/Mertk-mediated hematoma clearance warrants further investigation.

\section{MICROENVIRONMENTAL FACTORS ORCHESTRATE THE ERYTHROPHAGOCYTOSIS}

Efficient phagocytosis requires phagocytes to digest multiple cells continuously, especially in acute inflammation where the apoptotic cells-to-phagocytes ratio is high (Doran et al., 2020). The significance of erythrophagocytosis in this context also depends on whether the $\mathrm{M} \varphi$ can remove such a tremendous amount of erythrocyte before irreversible hemolytic-induced brain injury commences (Bulters et al., 2018). Of relevance are microenvironmental factors, including neuroinflammation and oxidative stress, that may alter phagocytic function and therefore serve as viable therapeutic targets.

\section{Inflammatory Mediators}

The correlation between $\mathrm{M} \varphi$ phenotypes and phagocytosis is complex. Erythrophagocytosis skewed M $\varphi$ toward the M2 phenotype, which reciprocally facilitated the removal of dying cells (Bensinger et al., 2009; Roszer, 2017; Chang C. F. et al., 2018). It possibly explains for the protective roles of M2-M $\varphi$ observed in both preclinical and clinical studies of stroke (Chernykh et al., 2016; Min et al., 2016; Bai et al., 2020). The cytokines involved in M1- and M2-M $\varphi$ activation could modulate erythrophagocytosis in ICH.

Interleukin-4 (IL-4) is the canonical activator of signal transducer and an activator of transcription 6 (STAT6), which is essential to the activation of M2 phenotype (Lawrence and Natoli, 2011). In ICH, exogenous IL-4 activated STAT6 and enhanced erythrophagocytosis in animal after ICH (Xu et al., 2020). The article revealed two potential mechanisms. Firstly, IL-4/STAT6 was observed to upregulate CD36, the scavenger receptor initiating phagocytosis. This may result from the direct binding of STAT6 to the promotor regions of CD36 gene (Szanto et al., 2010). Secondly, the study proved IL-1 receptor like 1 (ST2) was required for IL-4/STAT6-mediated clearance of 
erythrocyte. As ST2 promoted phagosome maturation (Buckley et al., 2011), it is likely that IL-4/STAT6 regulated phagosome infusion and thus enhancing phagocytosis in ICH. It is important to note that IL-4/STAT6 transcriptionally upregulates the antiinflammatory cytokines, which is likely to contribute to IL4/STAT6 mediated pro-phagocytosis effect. For example, Arg1 is required for STAT6-mediated pro-phagocytosis by $M \varphi$ in ischemic brain (Cai et al., 2019). The mechanism may link to the enzymatic role of Arg1 in arginine metabolism, which increased the $\mathrm{M} \varphi$ communication and resulted in continual phagocytosis (Yurdagul et al., 2020).

In the contrary, cytokines involved in M1-M $\varphi$ activation are potential to inhibit the removal of apoptotic cells. Amongst, TNF- $\alpha$ is the potential cytokine for targeting. TNF- $\alpha$ stimulates the M1 phenotype and is also regarded as a marker of M1-M $\varphi$ (Lan et al., 2017). In ICH, TNF- $\alpha$ downregulated CD36 in microglia and impaired its function in erythrophagocytosis (Fang et al., 2014). What's more, TNF- $\alpha$ upregulated the "don't eat-me" signal CD47 in vascular smooth muscle cells and renders less phagocytosis (Kojima et al., 2016). Thus, reverse the inhibition of TNF- $\alpha$ in erythrophagocytosis may be a potential approach to promote hematoma clearance. It is important to note that TNF- $\alpha$ inhibitors have been approved in the treatment of many diseases, such as ankylosing spondylitis and Crohn disease (Gerriets et al., 2021). However, whether these inhibitors can facilitate erythrophagocytosis and perform therapeutic effects remain unproved in $\mathrm{ICH}$.

\section{Oxidative Stress}

Oxidative stress is one of the major contributors toward pathological injury in ICH. The source of oxidative stress in $\mathrm{ICH}$ includes hemolytic products, mitochondria dysfunction, and $M \varphi$ (Hu et al., 2016). Hemolytic products, particularly iron, catalyze a sequence of reactions known as the Haber-Weiss reaction, yielding highly reactive oxygen species (ROS) (Xiong et al., 2014). Mitochondria dysfunction allows abnormal leakage of electrons from electron transport chain, overwhelming antioxidant system and leading to accumulation of ROS. M $\varphi$ also generates ROS by inhibiting oxidative metabolism (Zhou Y. et al., 2014) and processing large quantities by-products from the cell corpse (Splettstoesser and Schuff-Werner, 2002).

Oxidative stress have profound effects on $M \varphi$ (Vernon and Tang, 2013). In M $\varphi$, ROS is essential for bactericidal effects, whereas it can kill the phagocytes when the levels becomes overwhelming (Morrow et al., 2007; van-Charvet et al., 2010). What's more, the sudden onset of oxidative loading allows the transcription nuclear factor (NF)- $\kappa \mathrm{B}$ to transfer from cytoplasm to nucleus, initiating the transcription of proinflammatory mediators including TNF- $\alpha$ (Brigelius-Flohe and Flohe, 2011; Sivandzade et al., 2019). As previously discussed, TNF- $\alpha$ is potential to block phagocytosis. Moreover, oxidants may alter cell structures or destroy the signals required for phagocytes (Anderson et al., 2002; Schrijvers et al., 2005). In all, oxidative stress may be a detrimental factor dampening normal function of $\mathrm{M} \varphi$ and compromising the removal of apoptotic cells.

Thus, the restriction of oxidative stress serves as a potential approach to improve $\mathrm{M} \varphi$ viability and facilitate erythrophagocytosis in ICH. To achieve this, strengthening the self-defense ability of $\mathrm{M} \varphi$ is a reasonable direction. To counteract the oxidative stress, $M \varphi$ has developed the selfdefense mechanisms with the mainstay represented by $\mathrm{Nrf}-2$ (Virag et al., 2019). Treating microglia with the activator of Nrf-2 showed faster erythrophagocytosis speed (Zhao et al., 2015a). The roles of other self-defense mechanisms warrants more investigation. Besides, some substances that could sequestrates iron, the source of ROS, are also potent targets in facilitating erythrophagocytosis, such as lactoferrin. As a glycoprotein of transferrin family, lactoferrin was found to limit oxidative stress and promote microglia-mediated phagocytosis (Actor et al., 2009; Zhao et al., 2021). Lastly, Arg1, the M2 marker which is essential for arginine metabolism, could alleviate the oxidative stress by competing with inducible nitric oxide synthase (iNOS) for the arginine substrate (Corraliza et al., 1995; Morris and Jr, 2007). Given the role of arginine metabolism in phagocytosis (Yurdagul et al., 2020), this somehow reveals the internal links among inflammation, metabolism and oxidative stress in modulating phagocytosis.

\section{UPSTREAM REGULATORS FOR ERYTHROPHAGOCYTOSIS}

To initiate the erythrophagocytosis, the scavenger receptors in $\mathrm{M} \varphi$ drive the cell-to-cell interaction. These receptors are under controlled by by liver X receptor (LXR) and PPARs $(\alpha, \beta / \delta$ and $\gamma$ isotypes) (Roszer, 2017). Amongst, PPAR $\gamma$ is the most studied regulator in $\mathrm{ICH}$. Moreover, modulating the microenvironment factors shapes the function of $\mathrm{M} \varphi$ and enhances the phagocytosis efficacy. Nrf-2, as a powerful regulator of oxidative stress, has shown great therapeutic value in facilitating hematoma resolution and treating $\mathrm{ICH}$. Last, energy metabolism is a critical component of efficient phagocytosis (Jiang et al., 2013). The regulatory role of $\mathrm{AMPK}$, the energy sensor, in phagocytosis was also reviewed.

\section{PPAR $\gamma$}

PPAR $\gamma$ transcriptionally regulates genes that are critical to brain tissue repairment (Cai et al., 2018). Upon activation, PPAR $\gamma$ heterodimerizes with retinoid $\mathrm{X}$ receptor (RXR) and subsequently engages with the conserved DNA sequences, namely peroxisome proliferator response elements (PPREs). PPREs is located in the promoter regions of cytoprotective genes, including the scavenger receptors and catalase, with the latter is essential to minimize oxidative injury (Cai et al., 2018). Thus, PPAR $\gamma$ directly modulates phagocytosis and alleviates the oxidative stress, rendering it to be the most potent target in driving erythrophagocytosis and hematoma resolution in $\mathrm{ICH}$.

In $\mathrm{ICH}$, the activation of PPAR $\gamma$ could upregulate the scavenger receptors and facilitate erythrophagocytosis. Generally, the scavenger receptors for clearing apoptotic cells are regulated by liver X receptor (LXR) and PPARs ( $\alpha, \beta / \delta$ and $\gamma$ isotypes) with various combination patterns (Roszer, 2017): CD36 solely by PPAR $\gamma$, Axl by PPARs, and Mertk by PPARs and LXR. These patterns reflected the indispensable role of PPARs, especially 
PPAR $\gamma$, in regulating phagocytosis, which was supported by a number of ICH studies. Zhao et al. were the first to demonstrate that PPAR $\gamma$ agonist could upregulate CD36 in microglia, thereby facilitating erythrophagocytosis in vitro (Zhao et al., 2007b). This pioneering work further proved that PPAR $\gamma$ activation enhanced hematoma resolution and functional recovery in ICH. It paved the way for targeting $\mathrm{M} \varphi$-mediated hematoma resolution in ICH (Zhao et al., 2009). Subsequently, activation of PPAR $\gamma$ was observed to upregulate other scavenger receptors, Axl and Mertk, and expedite hematoma resolution in ICH (Zhuang et al., 2020). Moreover, the effects of PPAR $\gamma$ activation in erythrophagocytosis were also verified in other types of hemorrhagic stroke ( $\mathrm{Wu}$ et al., 2011; Flores et al., 2016). By activating PPAR $\gamma$, several pharmacological agents were found to confer protective effects in experimental ICH (Wang Y. et al., 2018; Fu et al., 2020; Zhao et al., 2020; Zhuang et al., 2020). Taken together, PPAR $\gamma$ activation is one of the mainstays of phagocytosis modulator in facilitating hematoma clearance after ICH.

In addition, PPAR $\gamma$ activation also alleviates inflammation and oxidative stress in ICH. For instance, PPAR $\gamma$ agonists reduce proinflammatory TNF- $\alpha$ and IL-1 $\beta$ expression (Zhao et al., 2007b). Mechanistically, PPAR $\gamma$ could prevent their nuclear receptor corepressor from being cleaved from the genes of TNF- $\alpha$ and IL-1 $\beta$ (Ghisletti et al., 2007; Jennewein et al., 2008). For oxidative stress, PPAR $\gamma$ reciprocally interacted with Nrf-2 and synergistically inhibited NFКB mediated-oxidative stress (Zhao et al., 2015c; Luo et al., 2021). Thus, PPAR $\gamma$ activation may also alleviate the inflammation and oxidative stress, producing a phagocytosis-friendly microenvironment for $\mathrm{M} \varphi$.

To magnify PPAR $\gamma$-mediated protective effects, both the endogenous and exogenous stimulators are viable targets. PPAR $\gamma$ is initially activated by the cell corpse-derived lipids in $M \varphi$ when phagocytosis commences (Kourtzelis et al., 2020). Interestingly, the PPAR $\gamma$ activity of $\mathrm{M} \varphi$ could also be modulated by other engulfed elements in addition to apoptotic cells. For instance, $\mathrm{M} \varphi$ could uptake the functional mitochondria and humanin released by astrocytes, which in turn upregulated the expression of PPAR $\gamma$ and its mediated phagocytosis in ICH (Jung et al., 2020). In addition, activating PPAR $\gamma$-targeted genes and PPAR $\gamma$-mediated hematoma resolution could also be achieved by activating its transcription partner, i.e., RXR (Chang et al., 2020; Ting et al., 2020). Lastly, a clinical trial using pioglitazone, a known PPAR-gamma agonist approved by FDA, has been conducted in $\mathrm{ICH}$ patients, aiming to reduce hematoma burden and improve outcomes (NCT00827892). Other nuclear receptors may also play a role in clearing apoptotic cells, such as LXR, retinoic acid receptor (RAR), and glucocorticoid receptor (GR) (Roszer, 2017). Their roles in ICH warrants further investigation.

\section{Nrf-2}

Nrf-2 is the principal transcriptional factor protecting cells from endogenous and exogenous stress (Kensler et al., 2007). Upon activation, Nrf2 heterodimerizes with the Maf family and binds to the antioxidant response elements (AREs) located in the regulatory regions of cytoprotective genes. These genes include antioxidant agents, such as catalase, HO-1, SOD, etc. (Zhao and Aronowski, 2013). Growing evidence supports the beneficial roles of Nrf2 in ICH. For instance, the absence of Nrf2 in rodents resulted in worse oxidative injury and more neurological deficits while the activation of Nrf2 reversed these effects in ICH (Wang et al., 2007; Zhao et al., 2007a; Iniaghe et al., 2015; Cheng et al., 2021).

Nrf-2 activation has also been proved to enhance the erythrophagocytosis by microglia and hematoma clearance in ICH (Zhao et al., 2015a). The effect of Nrf2 in promoting phagocytosis is partly CD36-dependent. The modulation of Nrf2 on CD36 may be PPAR $\gamma$-dependent or PPAR $\gamma$-independent, but this has not yet been confirmed (Ishii et al., 2004; Zhao et al., 2015c). Moreover, Nrf-2 regulates the genes responsible for detoxifying the blood products, including genes of ferritin, hemopexin and haptoglobin (Zhao and Aronowski, 2013; Deng

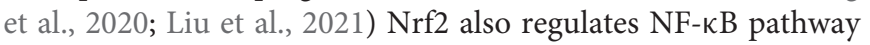
and alleviates inflammation in $\mathrm{ICH}$, rendering targeting Nrf2 as a highly promising approach to augmenting hematoma resolution (Cheng et al., 2021). Indeed, agonists of Nrf2, such as sulforaphane, dimethyl fumarate and others, have been shown to accelerate hematoma reduction (Zhao et al., 2015a,b).

\section{AMP-Activated Protein Kinase}

The reprograming of energy metabolic pathways is an emerging hallmark of anti-inflammatory (M2) M $\varphi$ (Devanney et al., 2020). Particularly, these anti-inflammatory cells exhibit increased mitochondria oxidative metabolism with much lower level of glycolysis, pinpointing the demand for efficient energy production for inflammation resolution and tissue repair. AMPactivated protein kinase (AMPK) attracts particular interest in fulfilling this energy demand of M $\varphi$ (Jiang et al., 2013). As an intracellular sensor of the "fuel status", AMPK is activated by the drop of ATP-to-ADP ratio, which occurs in conditions like mitochondria inhibition, exercise, and starvation (O'Neill and Hardie, 2013; Herzig and Shaw, 2018). To counteract energy insufficiency, AMPK switches on catabolic activities to generates energy more efficiently while dampening anabolic process that consumes ATP. Given the intimate connection between cellular metabolism and immune response, the role of AMPK in macrophage functions has been reviewed (O’Neill and Hardie, 2013).

AMP-activated protein kinase activation has been reported to skew macrophage activation toward the M2 phenotype and enhance hematoma resolution in ICH (Vaibhav et al., 2018). Several in vitro studies also demonstrated that AMPK activation contributed to the M2 M polarization and phagocytosis (Wan et al., 2013; Jin et al., 2014; Kaiser et al., 2020; Seneviratne et al., 2020). Consistently, the absence of AMPK- $\alpha 1$, the sole isoform expressed in $M \varphi$, impaired the anti-inflammatory and prophagocytic effect of $\mathrm{M} \varphi$ in various brain disorders (Vaibhav et al., 2018; Lv et al., 2020).

The mechanisms underlying AMPK's pro-phagocytosis effect are complex. On the one hand, AMPK cooperates with the transcriptional regulators (PPAR $\gamma$ and Nrf-2), modulating their downstream scavenger receptors including CD36 and Mertk 
(Wan et al., 2013; Galvan et al., 2014; Wang Y. J. et al., 2018; Kaiser et al., 2020; Lv et al., 2020). On the other hand, AMPK promotes the organization of cytoskeleton and the acidification of endosomal-lysosomal system, facilitating the ingestion and digestion of apoptotic cells (Labuzek et al., 2010; Bae et al., 2011). In sum, AMPK activation favors inflammation resolution and might enhance apoptotic cells clearance in ICH.

Pharmacological agents, such as AdipoRon and CTRP3, also showed potential in driving AMPK-mediated augmentation on phagocytosis or inflammation resolution and functional recovery in preclinical ICH studies (Wang et al., 2016; Zheng et al., 2019). Several clinical trials on RIC-mediated AMPK activation and hematoma clearance are ongoing: NCT04757597, NCT04657133, NCT03930940 and NCT03481777. However, the direct evidence on the pro-phagocytotic effects of AMPK activation warrants verification in $\mathrm{ICH}$.

\section{FUTURE DIRECTIONS}

Given the limited evidence available on ICH in this context, studies in other types of stroke could inspire the future research direction in ICH. Ischemic stroke is the main type of stroke and therefore has drawn greater scientific interest than other types of strokes. Regarding the phagocytosis of apoptotic cells (including injured RBCs and neurons), the underlying mechanisms appear to be similar and comparable between the two conditions. For example, the scavenger receptor CD36, which was widely studied in ICH, has also been proved to mediate phagocytosis in ischemic stroke (Woo et al., 2016). The phagocytosis effects of other molecules, such as Arg-1 and PPAR $\gamma$, were also reported in ischemic strokes (Cai et al., 2019; Zhang et al., 2019).

TABLE 2 | Merits and Demerits of M $\varphi$-mediated phagocytosis.

\begin{tabular}{|c|c|c|}
\hline $\begin{array}{l}\text { Effects of } \\
\text { phagocytosis }\end{array}$ & Targets & Details of effects \\
\hline \multirow[t]{3}{*}{ Merits } & Red blood cells & $\begin{array}{l}\text { Reduce clot toxicity and } \\
\text { Support the functional recovery } \\
\text { Zhao et al., 2009; Chang C. F. } \\
\text { et al., } 2018\end{array}$ \\
\hline & Neurons & $\begin{array}{l}\text { Reduce inflammatory cytokines } \\
\text { Lecca et al., 2018; } \\
\text { favor neurogenesis Sierra et al., } \\
2010 .\end{array}$ \\
\hline & Synapse & $\begin{array}{l}\text { Favor remyelination Natrajan } \\
\text { et al., } 2015 .\end{array}$ \\
\hline \multirow[t]{3}{*}{ Demerits } & Red blood cells & $\begin{array}{l}\text { Ferroptosis of phagocytes } \\
\text { Youssef et al., } 2018\end{array}$ \\
\hline & Neurons & $\begin{array}{l}\text { Neuron death Brown and } \\
\text { Neher, 2014; } \\
\text { delayed neuron loss Neher } \\
\text { et al., 2013; } \\
\text { degeneration of dopaminergic } \\
\text { neurons Barcia et al., 2013; }\end{array}$ \\
\hline & Synapse & $\begin{array}{l}\text { Synapse loss Hong et al., 2016; } \\
\text { demyelination Han et al., 2012; } \\
\text { worse functional outcome Shi } \\
\text { et al., } 2021 .\end{array}$ \\
\hline
\end{tabular}

Lastly, metabolic modulation, the phagocyted targets and the dynamic picture of pathophysiologic response after initial erythrophagocytosis are also important areas for future investigations.

\section{Better Understanding of the Metabolic Modulation in Erythrophagocytosis}

One of the priorities of future studies was to explore the basic mechanisms of erythrocytes removal in the hemorrhagic brain. Although the basic biology of efferocytosis has been deeply studied, whether it could be applied to post-ICH erythrophagocytosis needs more investigation (Doran et al., 2020; Kourtzelis et al., 2020). Amongst, this review underlines the significance of defining the metabolic adaption of $\mathrm{M} \varphi$ which contributes to ongoing phagocytosis. Then, we could explore the potential targets for modulating this adaption to achieve efficient phagocytosis in ICH. Interestingly, the roles of metabolic modulation in phagocytosis might explain the neuroprotective effects of some approved agents. For instance, uncoupling protein 2 (UCP2), a mitochondria membrane protein, has been observed to improve neurological outcomes in stroke (Mattiasson et al., 2003; Nakase et al., 2007; Mehta and Li, 2009; Zhao et al., 2019). This protein maintained the membrane potential and supported continuous phagocytosis (Krauss et al., 2002, 2005; Park et al., 2011). However, whether UCP2 plays a role in facilitating phagocytosis in ICH is undefined.

\section{Better Understanding of the Phagocyted Targets}

Erythrophagocytosis shares similar mechanisms in phagocytosing different apoptotic cells. Thus, enhancing the erythrophagocytosis signals can also eliminate other apoptotic cells nearby (Galloway et al., 2019). In ICH, the hematoma usually contains unvital neurons due to mechanical force and/or neurotoxicity of hematoma (Xi et al., 2006). Historically, eliminating the dying brain cells and synapses was regarded as a beneficial process since it would prevent self-antigen exposure and establish new homeostasis in the brain (review by Galloway et al. (2019)). However, the adverse effects of eliminating apoptotic neurons have recently been demonstrated in several brain disorders, including Alzheimer's disease, multiple sclerosis, and strokes (Neher et al., 2013; Hong et al., 2016; Werneburg et al., 2020). The phagocytosis of "stressed-but-viable" neurons by $M \varphi$ results in cell death, called "phagoptosis," which could lead to delayed neuron loss (Brown and Neher, 2012; Neher et al., 2013). In ICH, a recent study demonstrated that the Mertkdependent phagocytosis of synapse worsened the neurological outcome in animals after stroke (Shi et al., 2021). Table 2 outlines other adverse effects of phagocytosis which may be potentially contradictory to this review's central tenet and suggest the need for a more specific phagocytosis system. Moreover, a systemic upregulation of erythrophagocytosis might disturb the physical removal of RBCs by splenic red pulp macrophage, since it involves the same phagocytosis-relevant receptors (Klei et al., 2017). Thus, future studies need to search for a pro-phagocytotic drug with localized specificity. 


\section{CONCLUSION: ERYTHROPHAGOCYTOSIS AS A SPATIOTEMPORALLY DEVELOPING STORY}

The foregoing review suggests that it is necessary to consider erythrophagocytosis in ICH as a spatiotemporally progressing event. There are mainly two concerns. Firstly, how could the M $\varphi$ completely remove the damaged RBCs in a situation where the latter vastly outnumbers the former? Moreover, the population of $\mathrm{M} \varphi$ might be further reduced by the primary injury or the intracellular iron toxicity (van-Charvet et al., 2010; Youssef et al., 2018). To prevent the overwhelming of phagocytotic machinery, the number of $\mathrm{M} \varphi$ must be regulated to obtain sufficient phagocytotic capacity (Morioka et al., 2019). Therefore, therapies aimed at maximizing the number of functional phagocytes could improve RBC removal and should become a focus of future research. Inspiringly, this idea of introducing more functional $\mathrm{M} \varphi$ has recently been found to facilitate animal recovery from traumatic brain injury ( $\mathrm{Li} \mathrm{Z}$. et al., 2021). Another layer of complexity lies in the fact that these immune cells tend to execute time-dependent effects in cerebrovascular injury, i.e., worsening

\section{REFERENCES}

Actor, J. K., Hwang, S. A., and Kruzel, M. L. (2009). Lactoferrin as a natural immune modulator. Curr. Pharm. Des. 15, 1956-1973. doi: 10.2174/ 138161209788453202

Alessio, M., De Monte, L., Scirea, A., Gruarin, P., Tandon, N. N., and Sitia, R. (1996). Synthesis, processing, and intracellular transport of CD36 during monocytic differentiation. J. Biol. Chem. 271, 1770-1775. doi: 10.1074/jbc.271. 3.1770

Anderson, H. A., Englert, R., Gursel, I., and Shacter, E. (2002). Oxidative stress inhibits the phagocytosis of apoptotic cells that have externalized phosphatidylserine. Cell Death Differ. 9, 616-625. doi: 10.1038/sj.cdd.440 1013

Bae, H. B., Zmijewski, J. W., Deshane, J. S., Tadie, J. M., Chaplin, D. D., Takashima, S., et al. (2011). AMP-activated protein kinase enhances the phagocytic ability of macrophages and neutrophils. FASEB J. 25, 4358-4368. doi: 10.1096/fj.11190587

Bai, Q., Xue, M., and Yong, V. W. (2020). Microglia and macrophage phenotypes in intracerebral haemorrhage injury: therapeutic opportunities. Brain 143, 1297-1314. doi: 10.1093/brain/awz393

Barcia, C., Ros, C. M., Ros-Bernal, F., Gomez, A., Annese, V., Carrillo-de Sauvage, M. A., et al. (2013). Persistent phagocytic characteristics of microglia in the substantia nigra of long-term Parkinsonian macaques. J. Neuroimmunol. 261, 60-66. doi: 10.1016/j.jneuroim.2013.05.001

Bennett, M. L., Bennett, F. C., Liddelow, S. A., Ajami, B., Zamanian, J. L., Fernhoff, N. B., et al. (2016). New tools for studying microglia in the mouse and human CNS. Proc. Natl. Acad. Sci. U. S. A. 113, E1738-E1746. doi: 10.1073/pnas. 1525528113

Bensinger, A. G. N. S. J., Hong, C., Beceiro, S., Bradley, M. N., Zelcer, N., Deniz, J., et al. (2009). Apoptotic cells promote their own clearance and immune tolerance through activation of the nuclear receptor LXR. Immunity 31, 245258. doi: 10.1016/j.immuni.2009.06.018

Boas, F. E., Forman, L., and Beutler, E. (1998). Phosphatidylserine exposure and red cell viability in red cell aging and in hemolytic anemia. Proc. Natl. Acad. Sci. U. S. A. 95, 3077-3081. doi: 10.1073/pnas.95.6.3077

Brigelius-Flohe, R., and Flohe, L. (2011). Basic Principles and Emerging Concepts in the Redox Control of Transcription Factors. Antioxid. Redox Signal. 15, 2335-2381. doi: 10.1089/ars.2010.3534 the brain injury at acute phase but repairing the tissue at later stage (Mastorakos et al., 2021). One should therefore also take into consideration the optimal therapeutic time window when attempting to bring these cells into the brain. Secondly, what is the fate of $\mathrm{M} \varphi$ after engulfing RBCs in ICH? Although $\mathrm{M} \varphi$ could digest RBCs into the degradation products within themselves, could they process the blood components, especially iron, in a non-toxic way? Microglia contains the system for transporting and storing the iron in the normal brain, which is critical to the brain iron cycle and homeostasis (Winn et al., 2020). However, it remains unknown whether microglia could maintain its own homeostasis rather than undergoing iron-dependent cell death, namely "ferroptosis" in ICH (Youssef et al., 2018). Further studies are needed to achieve a better understanding of erythrophagocytosis and translate its therapeutic value to clinical practice.

\section{AUTHOR CONTRIBUTIONS}

JL and ZZ wrote the manuscript. GL supervised the drafting and revision of the manuscript. All authors contributed to the article and approved the submitted version.

Brott, T., Broderick, J., Kothari, R., Barsan, W., Tomsick, T., Sauerbeck, L., et al. (1997). Early hemorrhage growth in patients with intracerebral hemorrhage. Stroke 28, 1-5. doi: 10.1161/01.str.28.1.1

Brown, E. J., and Frazier, W. A. (2001). Integrin-associated protein (CD47) and its ligands. Trends Cell Biol. 11, 130-135. doi: 10.1016/s0962-8924(00)01906-1

Brown, G. C., and Neher, J. J. (2012). Eaten alive! Cell death by primary phagocytosis: 'phagoptosis'. Trends Biochem. Sci. 37, 325-332. doi: 10.1016/j. tibs.2012.05.002

Brown, G. C., and Neher, J. J. (2014). Microglial phagocytosis of live neurons. Nat. Rev. Neurosci. 15, 209-216. doi: 10.1038/nrn3710

Buckley, J. M., Liu, J. H., Li, C. H., Blankson, S., Wu, Q. D., Jiang, Y., et al. (2011). Increased susceptibility of ST2-deficient mice to polymicrobial sepsis is associated with an impaired bactericidal function. J. Immunol. 187, 4293-4299. doi: 10.4049/jimmunol.1003872

Bulters, D., Gaastra, B., Zolnourian, A., Alexander, S., Ren, D., Blackburn, S. L., et al. (2018). Haemoglobin scavenging in intracranial bleeding: biology and clinical implications. Nat. Rev. Neurol. 14, 416-432. doi: 10.1038/s41582-0180020-0

Cai, B., Thorp, E. B., Doran, A. C., Subramanian, M., Sansbury, B. E., Lin, C. S., et al. (2016). MerTK cleavage limits proresolving mediator biosynthesis and exacerbates tissue inflammation. Proc. Natl. Acad. Sci. U. S. A. 113, 6526-6531. doi: 10.1073/pnas.1524292113

Cai, W., Dai, X., Chen, J., Zhao, J., Xu, M., Zhang, L., et al. (2019). STAT6/Arg1 promotes microglia/macrophage efferocytosis and inflammation resolution in stroke mice. JCI Insight 4:e131355. doi: 10.1172/jci.insight.131355

Cai, W., Yang, T., Liu, H., Han, L., Zhang, K., Hu, X., et al. (2018). Peroxisome proliferator-activated receptor gamma (PPARgamma): a master gatekeeper in CNS injury and repair. Prog. Neurobiol. 163-164, 27-58. doi: 10.1016/j. pneurobio.2017.10.002

Cao, S., Zheng, M., Hua, Y., Chen, G., Keep, R. F., and Xi, G. (2016). Hematoma Changes During Clot Resolution After Experimental Intracerebral Hemorrhage. Stroke 47, 1626-1631. doi: 10.1161/STROKEAHA.116.013146

Chang, C. F., Goods, B. A., Askenase, M. H., Hammond, M. D., Renfroe, S. C., Steinschneider, A. F., et al. (2018). Erythrocyte efferocytosis modulates macrophages towards recovery after intracerebral hemorrhage. J. Clin. Invest. 128, 607-624. doi: 10.1172/JCI95612

Chang, C. F., Massey, J., Osherov, A., Angenendt da Costa, L. H., and Sansing, L. H. (2020). Bexarotene Enhances Macrophage Erythrophagocytosis and Hematoma 
Clearance in Experimental Intracerebral Hemorrhage. Stroke 51, 612-618. doi: 10.1161/strokeaha.119.027037

Chang, R., Castillo, J., Zambon, A. C., Krasieva, T. B., Fisher, M. J., and Sumbria, R. K. (2018). Brain Endothelial Erythrophagocytosis and Hemoglobin Transmigration Across Brain Endothelium: implications for Pathogenesis of Cerebral Microbleeds. Front. Cell Neurosci. 12:279. doi: 10.3389/fncel.2018. 00279

Chen, J., Koduri, S., Dai, S., Toyota, Y., Hua, Y., Chaudhary, N., et al. (2021). Intrahematomal White Matter Tracts Act As a Scaffold for Macrophage Infiltration After Intracerebral Hemorrhage. Transl. Stroke Res. 12, 858-865. doi: 10.1007/ s12975-020-00870-5

Cheng, Y., Liu, M., Tang, H., Chen, B., Yang, G., Zhao, W., et al. (2021). iTRAQ-Based Quantitative Proteomics Indicated Nrf2/OPTN-Mediated Mitophagy Inhibits NLRP3 Inflammasome Activation after Intracerebral Hemorrhage. Oxid. Med. Cell. Longev. 2021:6630281. doi: 10.1155/2021/663 0281

Chernykh, E. R., Shevela, E. Y., Starostina, N. M., Morozov, S. A., Davydova, M. N., Menyaeva, E. V., et al. (2016). Safety and Therapeutic Potential of M2 Macrophages in Stroke Treatment. Cell Transplant. 25, 1461-1471. doi: 10.3727/096368915X690279

Corraliza, I. M., Soler, G., Eichmann, K., and Modolell, M. (1995). Arginase induction by suppressors of nitric oxide synthesis (IL-4, IL-10 and PGE2) in murine bone-marrow-derived macrophages. Biochem. Biophys. Res. Commun. 206, 667-673. doi: 10.1006/bbrc.1995.1094

Cugurra, A., Mamuladze, T., Rustenhoven, J., Dykstra, T., Beroshvili, G., Greenberg, Z. J., et al. (2021). Skull and vertebral bone marrow are myeloid cell reservoirs for the meninges and CNS parenchyma. Science 373:eabf7844. doi: 10.1126/science.abf7844

de Back, D. Z., Kostova, E. B., van Kraaij, M., van den Berg, T. K., and van Bruggen, R. (2014). Of macrophages and red blood cells; a complex love story. Front. Physiol. 5:9. doi: 10.3389/fphys.2014.00009

Deng, S., Sherchan, P., Jin, P., Huang, L., Travis, Z., Zhang, J. H., et al. (2020). Recombinant CCL17 Enhances Hematoma Resolution and Activation of CCR4/ERK/Nrf2/CD163 Signaling Pathway After Intracerebral Hemorrhage in Mice. Neurotherapeutics 17, 1940-1953. doi: 10.1007/s13311-020-00908-4

Devanney, N. A., Stewart, A. N., and Gensel, J. C. (2020). Microglia and macrophage metabolism in CNS injury and disease: the role of immunometabolism in neurodegeneration and neurotrauma. Exp. Neurol. 329:9. doi: 10.1016/j.expneurol.2020.113310

Di Stasi, R., De Rosa, L., and D'Andrea, L. D. (2020). Therapeutic aspects of the Axl/Gas6 molecular system. Drug Discov. Today 25, 2130-2148. doi: 10.1016/j. drudis.2020.09.022

Doran, A. C., Yurdagul, A., and Tabas, I. (2020). Efferocytosis in health and disease. Nat. Rev. Immunol. 20, 254-267. doi: 10.1038/s41577-019-0240-6

Engelhardt, B. (2008). Immune cell entry into the central nervous system: involvement of adhesion molecules and chemokines. J. Neurol. Sci. 274, 23-26. doi: 10.1016/j.jns.2008.05.019

Fang, H., Chen, J., Lin, S., Wang, P., Wang, Y., Xiong, X., et al. (2014). CD36mediated hematoma absorption following intracerebral hemorrhage: negative regulation by TLR4 signaling. J. Immunol. 192, 5984-5992. doi: 10.4049/ jimmunol.1400054

Figueiredo, R. T., Fernandez, P. L., Mourao-Sa, D. S., Porto, B. N., Dutra, F. F., Alves, L. S., et al. (2007). Characterization of heme as activator of Tolllike receptor 4. J. Biol. Chem. 282, 20221-20229. doi: 10.1074/jbc.M61073 7200

Flores, J. J., Klebe, D., Rolland, W. B., Lekic, T., Krafft, P. R., and Zhang, J. H. (2016). PPARgamma-induced upregulation of CD36 enhances hematoma resolution and attenuates long-term neurological deficits after germinal matrix hemorrhage in neonatal rats. Neurobiol. Dis. 87, 124-133. doi: 10.1016/j.nbd. 2015.12.015

Fourgeaud, L., Traves, P. G., Tufail, Y., Leal-Bailey, H., Lew, E. D., Burrola, P. G., et al. (2016). TAM receptors regulate multiple features of microglial physiology. Nature 532, 240-244. doi: 10.1038/nature17630

Fu, P., Liu, J., Bai, Q., Sun, X., Yao, Z., Liu, L., et al. (2020). Long-term outcomes of monascin - a novel dual peroxisome proliferator-activated receptor gamma/nuclear factor-erythroid 2 related factor-2 agonist in experimental intracerebral hemorrhage. Ther. Adv. Neurol. Disord. 13:1756286420921083. doi: $10.1177 / 1756286420921083$
Galloway, D. A., Phillips, A. E. M., Owen, D. R. J., and Moore, C. S. (2019). Phagocytosis in the Brain: homeostasis and Disease. Front. Immunol. 10:790. doi: $10.3389 /$ fimmu. 2019.00790

Galvan, M. D., Hulsebus, H., Heitker, T., Zeng, E. L., and Bohlson, S. S. (2014). Complement Protein Clq and Adiponectin Stimulate Mer Tyrosine KinaseDependent Engulfment of Apoptotic Cells through a Shared Pathway. J. Innate Immun. 6, 780-792. doi: 10.1159/000363295

Gardai, S. J., McPhillips, K. A., Frasch, S. C., Janssen, W. J., Starefeldt, A., MurphyUllrich, J. E., et al. (2005). Cell-surface calreticulin initiates clearance of viable or apoptotic cells through trans-activation of LRP on the phagocyte. Cell 123, 321-334. doi: 10.1016/j.cell.2005.08.032

Gerriets, V., Bansal, P., Goyal, A., and Khaddour, K. (2021). Tumor Necrosis Factor Inhibitors. Treasure Island: StatPearls.

Ghisletti, S., Huang, W., Ogawa, S., Pascual, G., Lin, M. E., Willson, T. M., et al. (2007). Parallel SUMOylation-dependent pathways mediate gene- and signalspecific transrepression by LXRs and PPARgamma. Mol. Cell 25, 57-70. doi: 10.1016/j.molcel.2006.11.022

Gliem, M., Mausberg, A. K., Lee, J. I., Simiantonakis, I., van Rooijen, N., Hartung, H. P., et al. (2012). Macrophages prevent hemorrhagic infarct transformation in murine stroke models. Ann. Neurol. 71, 743-752. doi: 10.1002/ana.23529

Han, D., Liu, H., and Gao, Y. (2020). The role of peripheral monocytes and macrophages in ischemic stroke. Neurol. Sci. 41, 3589-3607. doi: 10.1007/ s10072-020-04777-9

Han, M. H., Lundgren, D. H., Jaiswal, S., Chao, M., Graham, K. L., Garris, C. S., et al. (2012). Janus-like opposing roles of CD47 in autoimmune brain inflammation in humans and mice. J. Exp. Med. 209, 1325-1334. doi: 10.1084/jem.20101974

Hemphill, J. C. III, Greenberg, S. M., Anderson, C. S., Becker, K., Bendok, B. R., Cushman, M., et al. (2015). Guidelines for the Management of Spontaneous Intracerebral Hemorrhage: a Guideline for Healthcare Professionals From the American Heart Association/American Stroke Association. Stroke 46, 20322060. doi: 10.1161/str.0000000000000069

Herzig, S., and Shaw, R. J. (2018). AMPK: guardian of metabolism and mitochondrial homeostasis. Nat. Rev. Mol. Cell Biol. 19, 121-135. doi: 10.1038/ nrm.2017.95

Herzog, C., Garcia, L. P., Keatinge, M., Greenald, D., Moritz, C., Peri, F., et al. (2019). Rapid clearance of cellular debris by microglia limits secondary neuronal cell death after brain injury in vivo. Development 146:dev174698. doi: $10.1242 / \operatorname{dev} .174698$

Hochreiter-Hufford, A., and Ravichandran, K. S. (2013). Clearing the dead: apoptotic cell sensing, recognition, engulfment, and digestion. Cold Spring Harb. Perspect. Biol. 5:a008748. doi: 10.1101/cshperspect.a008748

Hong, S., Beja-Glasser, V. F., Nfonoyim, B. M., Frouin, A., Li, S., Ramakrishnan, S., et al. (2016). Complement and microglia mediate early synapse loss in Alzheimer mouse models. Science 352, 712-716. doi: 10.1126/science.aad8373

Hu, X., Tao, C., Gan, Q., Zheng, J., Li, H., and You, C. (2016). Oxidative Stress in Intracerebral Hemorrhage: sources, Mechanisms, and Therapeutic Targets. Oxid. Med. Cell. Longev. 2016:3215391. doi: 10.1155/2016/3215391

Iniaghe, L. O., Krafft, P. R., Klebe, D. W., Omogbai, E. K. I., Zhang, J. H., and Tang, J. (2015). Dimethyl fumarate confers neuroprotection by casein kinase 2 phosphorylation of Nrf2 in murine intracerebral hemorrhage. Neurobiol. Dis. 82, 349-358. doi: 10.1016/j.nbd.2015.07.001

Ishii, T., Itoh, K., Ruiz, E., Leake, D. S., Unoki, H., Yamamoto, M., et al. (2004). Role of Nrf2 in the regulation of CD36 and stress protein expression in murine macrophages: activation by oxidatively modified LDL and 4-hydroxynonenal. Circ. Res. 94, 609-616. doi: 10.1161/01.RES.0000119171.44657.45

Jennewein, C., Kuhn, A. M., Schmidt, M. V., Meilladec-Jullig, V., von Knethen, A., Gonzalez, F. J., et al. (2008). Sumoylation of peroxisome proliferatoractivated receptor gamma by apoptotic cells prevents lipopolysaccharideinduced NCoR removal from kappaB binding sites mediating transrepression of proinflammatory cytokines. J. Immunol. 181, 5646-5652. doi: 10.4049/ jimmunol.181.8.5646

Jiang, S. N., Park, D. W., Stigler, W. S., Creighton, J., Ravi, S., Darley-Usmar, V., et al. (2013). Mitochondria and AMP-activated Protein Kinase-dependent Mechanism of Efferocytosis. J. Biol. Chem. 288, 26013-26026. doi: 10.1074/jbc. M113.489468

Jin, Q., Cheng, J., Liu, Y., Wu, J., Wang, X. Y., Wei, S. W., et al. (2014). Improvement of functional recovery by chronic metformin treatment is associated with enhanced alternative activation of microglia/macrophages and 
increased angiogenesis and neurogenesis following experimental stroke. Brain Behav. Immun. 40, 131-142. doi: 10.1016/j.bbi.2014.03.003

Jing, C., Bian, L., Wang, M., Keep, R. F., Xi, G., and Hua, Y. (2019). Enhancement of Hematoma Clearance With CD47 Blocking Antibody in Experimental Intracerebral Hemorrhage. Stroke 50, 1539-1547. doi: 10.1161/strokeaha.118. 024578

Jung, J. E., Sun, G., Bautista Garrido, J., Obertas, L., Mobley, A.S., Ting, S. M., et al. (2020). The Mitochondria-Derived Peptide Humanin Improves Recovery from Intracerebral Hemorrhage: implication of Mitochondria Transfer and Microglia Phenotype Change. J. Neurosci. 40, 2154-2165. doi: 10.1523/ JNEUROSCI.2212-19.2020

Kaiser, S., Selzner, L., Weber, J., and Schallner, N. (2020). Carbon monoxide controls microglial erythrophagocytosis by regulating CD36 surface expression to reduce the severity of hemorrhagic injury. Glia 68, 2427-2445. doi: 10.1002/ glia. 23864

Katsu, M., Niizuma, K., Yoshioka, H., Okami, N., Sakata, H., and Chan, P. H. (2010). Hemoglobin-induced oxidative stress contributes to matrix metalloproteinase activation and blood-brain barrier dysfunction in vivo. J. Cereb. Blood Flow Metab. 30, 1939-1950. doi: 10.1038/jcbfm.20 10.45

Kensler, T. W., Wakabayashi, N., and Biswal, S. (2007). Cell survival responses to environmental stresses via the Keap1-Nrf2-ARE pathway. Annu. Rev. Pharmacol. Toxicol. 47, 89-116. doi: 10.1146/annurev.pharmtox.46.120604. 141046

Klei, T. R., Meinderts, S. M., van den Berg, T. K., and van Bruggen, R. (2017). From the Cradle to the Grave: the Role of Macrophages in Erythropoiesis and Erythrophagocytosis. Front. Immunol. 8:73. doi: 10.3389/fimmu.2017.00073

Kojima, Y., Volkmer, J. P., McKenna, K., Civelek, M., Lusis, A. J., Miller, C. L., et al. (2016). CD47-blocking antibodies restore phagocytosis and prevent atherosclerosis. Nature 536, 86-90. doi: 10.1038/nature18935

Kourtzelis, I., Hajishengallis, G., and Chavakis, T. (2020). Phagocytosis of Apoptotic Cells in Resolution of Inflammation. Front. Immunol. 11:553. doi: 10.3389/fimmu.2020.00553

Krauss, S., Zhang, C. Y., and Lowell, B. B. (2002). A significant portion of mitochondrial proton leak in intact thymocytes depends on expression of UCP2. Proc. Natl. Acad. Sci. U. S. A. 99, 118-122. doi: 10.1073/pnas.012410699

Krauss, S., Zhang, C. Y., and Lowell, B. B. (2005). The mitochondrial uncouplingprotein homologues. Nat. Rev. Mol. Cell Biol. 6, 248-261. doi: 10.1038/nrm1592

Kwon, M. S., Woo, S. K., Kurland, D. B., Yoon, S. H., Palmer, A. F., Banerjee, U., et al. (2015). Methemoglobin is an endogenous Toll-like receptor 4 ligandrelevance to subarachnoid hemorrhage. Int. J. Mol. Sci. 16, 5028-5046. doi: 10.3390/ijms16035028

Labuzek, K., Liber, S., Gabryel, B., Adamczyk, J., and Okopień, B. (2010). Metformin increases phagocytosis and acidifies lysosomal/endosomal compartments in AMPK-dependent manner in rat primary microglia. Naunyn Schmiedebergs Arch. Pharmacol. 381, 171-186.

Lan, X., Han, X., Li, Q., Yang, Q.-W., and Wang, J. (2017). Modulators of microglial activation and polarization after intracerebral haemorrhage. Nat. Rev. Neurol. 13, 420-433. doi: 10.1038/nrneurol.2017.69

Lang, F., Abed, M., Lang, E., and Foller, M. (2014). Oxidative stress and suicidal erythrocyte death. Antioxid. Redox Signal. 21, 138-153. doi: 10.1089/ars.2013. 5747

Lawrence, T., and Natoli, G. (2011). Transcriptional regulation of macrophage polarization: enabling diversity with identity. Nat. Rev. Immunol. 11, 750-761. doi: $10.1038 /$ nri3088

Lecca, D., Janda, E., Mulas, G., Diana, A., Martino, C., Angius, F., et al. (2018). Boosting phagocytosis and anti-inflammatory phenotype in microglia mediates neuroprotection by PPARgamma agonist MDG548 in Parkinson's disease models. Br. J. Pharmacol. 175, 3298-3314. doi: 10.1111/bph.14214

Lemke, G., and Burstyn-Cohen, T. (2010). TAM receptors and the clearance of apoptotic cells. Ann. N. Y. Acad. Sci. 1209, 23-29. doi: 10.1111/j.1749-6632. 2010.05744.x

Li, Q., Lan, X., Han, X., and Wang, J. (2018). Expression of Tmem119/Sall1 and Ccr2/CD69 in FACS-Sorted Microglia- and Monocyte/Macrophage-Enriched Cell Populations After Intracerebral Hemorrhage. Front. Cell Neurosci. 12:520. doi: $10.3389 /$ fncel.2018.00520

Li, Q., Lan, X., Han, X., Durham, F., Wan, J., Weiland, A., et al. (2021). Microgliaderived interleukin-10 accelerates post-intracerebral hemorrhage hematoma clearance by regulating CD36. Brain Behav. Immun. 94, 437-457. doi: 10.1016/ j.bbi.2021.02.001

Li, Z., Xiao, J., Xu, X., Li, W., Zhong, R., Qi, L., et al. (2021). 6, and TGF- $\beta$ promote generation of a new subset of tissue repair macrophage for traumatic brain injury recovery. Sci. Adv. 7:eabb6260. doi: 10.1126/sciadv.abb6260

Liu, S., Flores, J. J., Li, B., Deng, S., Zuo, G., Peng, J., et al. (2021). IL-20R Activation via rIL-19 Enhances Hematoma Resolution through the IL-20R1/ERK/Nrf2 Pathway in an Experimental GMH Rat Pup Model. Oxid. Med. Cell Longev. 2021:5913424. doi: 10.1155/2021/5913424

Loftspring, M. C., McDole, J., Lu, A., Clark, J. F., and Johnson, A. J. (2009). Intracerebral hemorrhage leads to infiltration of several leukocyte populations with concomitant pathophysiological changes. J. Cereb. Blood Flow Metab. 29, 137-143. doi: 10.1038/jcbfm.2008.114

Luo, X., Wu, J., and Wu, G. (2021). PPAR $\gamma$ activation suppresses the expression of MMP9 by downregulating NF-кB post intracerebral hemorrhage. Neurosci. Lett. 752:135770. doi: 10.1016/j.neulet.2021.135770

Lv, J. L., Wang, W., Zhu, X. L., Xu, X. J., Yan, Q. Y., Lu, J., et al. (2020). DW14006 as a direct AMPK alpha 1 activator improves pathology of AD model mice by regulating microglial phagocytosis and neuroinflammation. Brain Behav. Immun. 90, 55-69. doi: 10.1016/j.bbi.2020.07.041

Marnett, L. J., Riggins, J. N., and West, J. D. (2003). Endogenous generation of reactive oxidants and electrophiles and their reactions with DNA and protein. J. Clin. Invest. 111, 583-593. doi: 10.1172/JCI18022

Mastorakos, P., Mihelson, N., Luby, M., Burks, S. R., Johnson, K., Hsia, A. W., et al. (2021). Temporally distinct myeloid cell responses mediate damage and repair after cerebrovascular injury. Nat. Neurosci. 24, 245-258. doi: 10.1038/s41593020-00773-6

Mattiasson, G., Shamloo, M., Gido, G., Mathi, K., Tomasevic, G., Yi, S., et al. (2003). Uncoupling protein-2 prevents neuronal death and diminishes brain dysfunction after stroke and brain trauma. Nat. Med. 9, 1062-1068. doi: 10. 1038/nm903

Mehta, S. L., and Li, P. A. (2009). Neuroprotective role of mitochondrial uncoupling protein 2 in cerebral stroke. J. Cereb. Blood Flow Metab. 29, 1069-1078. doi: 10.1038/jcbfm.2009.4

Min, H., Jang, Y. H., Cho, I. H., Yu, S. W., and Lee, S. J. (2016). Alternatively activated brain-infiltrating macrophages facilitate recovery from collagenaseinduced intracerebral hemorrhage. Mol. Brain 9:42. doi: 10.1186/s13041-0160225-3

Miro-Mur, F., Perez-de-Puig, I., Ferrer-Ferrer, M., Urra, X., Justicia, C., Chamorro, A., et al. (2016). Immature monocytes recruited to the ischemic mouse brain differentiate into macrophages with features of alternative activation. Brain Behav. Immun. 53, 18-33. doi: 10.1016/j.bbi.2015.08.010

Morgenstern, L. B., Demchuk, A. M., Kim, D. H., Frankowski, R. F., and Grotta, J. C. (2001). Rebleeding leads to poor outcome in ultra-early craniotomy for intracerebral hemorrhage. Neurology 56, 1294-1299. doi: 10.1212/wnl.56.10. 1294

Morioka, S., Maueroder, C., and Ravichandran, K. S. (2019). Living on the Edge: efferocytosis at the Interface of Homeostasis and Pathology. Immunity 50, 1149-1162. doi: 10.1016/j.immuni.2019.04.018

Morris, S. M. Jr. (2007). Arginine metabolism: boundaries of our knowledge. J. Nutr. 137, 1602S-1609S. doi: 10.1093/jn/137.6.1602S

Morrow, D. M. P., Entezari-Zaher, T., Romashko, J., Azghani, A. O., Javdan, M., Ulloa, L., et al. (2007). Antioxidants preserve macrophage phagocytosis of Pseudomonas aeruginosa during hyperoxia. Free Radic. Biol. Med. 42, 13381349. doi: 10.1016/j.freeradbiomed.2007.01.031

Mracsko, E., Javidi, E., Na, S. Y., Kahn, A., Liesz, A., and Veltkamp, R. (2014). Leukocyte invasion of the brain after experimental intracerebral hemorrhage in mice. Stroke 45, 2107-2114. doi: 10.1161/STROKEAHA.114.005801

Nakamura, T., Keep, R. F., Hua, Y., Hoff, J. T., and Xi, G. (2005). Oxidative DNA injury after experimental intracerebral hemorrhage. Brain Res. 1039, 30-36. doi: 10.1016/j.brainres.2005.01.036

Nakase, T., Yoshida, Y., and Nagata, K. (2007). Amplified expression of uncoupling proteins in human brain ischemic lesions. Neuropathology 27, 442-447. doi: 10.1111/j.1440-1789.2007.00815.x

Natrajan, M. S., de la Fuente, A. G., Crawford, A. H., Linehan, E., Nunez, V., Johnson, K. R., et al. (2015). Retinoid X receptor activation reverses agerelated deficiencies in myelin debris phagocytosis and remyelination. Brain 138, 3581-3597. doi: 10.1093/brain/awv289 
Neher, J. J., Emmrich, J. V., Fricker, M., Mander, P. K., Thery, C., and Brown, G. C. (2013). Phagocytosis executes delayed neuronal death after focal brain ischemia. Proc. Natl. Acad. Sci. U. S. A. 110, E4098-E4107. doi: 10.1073/pnas.1308679110

Ni, W., Mao, S., Xi, G., Keep, R. F., and Hua, Y. (2016). Role of Erythrocyte CD47 in Intracerebral Hematoma Clearance. Stroke 47, 505-511. doi: 10.1161/ STROKEAHA.115.010920

Nilsson, A., Vesterlund, L., and Oldenborg, P. A. (2012). Macrophage expression of LRP1, a receptor for apoptotic cells and unopsonized erythrocytes, can be regulated by glucocorticoids. Biochem. Biophys. Res. Commun. 417, 1304-1309. doi: 10.1016/j.bbrc.2011.12.137

Oldenborg, P. A. (2004). Role of CD47 in erythroid cells and in autoimmunity. Leuk. Lymphoma 45, 1319-1327. doi: 10.1080/1042819042000201989

Olsson, M., Nilsson, A., and Oldenborg, P. A. (2006). Target cell CD47 regulates macrophage activation and erythrophagocytosis. Transfus. Clin. Biol. 13, 39-43. doi: 10.1016/j.tracli.2006.02.013

O'Neill, L. A., and Hardie, D. G. (2013). Metabolism of inflammation limited by AMPK and pseudo-starvation. Nature 493, 346-355. doi: 10.1038/nature11862

Paolicelli, R. C., Bolasco, G., Pagani, F., Maggi, L., Scianni, M., Panzanelli, P., et al. (2011). Synaptic pruning by microglia is necessary for normal brain development. Science 333, 1456-1458. doi: 10.1126/science.1202529

Park, D., Han, C. Z., Elliott, M. R., Kinchen, J. M., Trampont, P. C., Das, S., et al. (2011). Continued clearance of apoptotic cells critically depends on the phagocyte Ucp2 protein. Nature 477, 220-224. doi: 10.1038/nature10340

Rolls, A., Shechter, R., and Schwartz, M. (2009). The bright side of the glial scar in CNS repair. Nat. Rev. Neurosci. 10, 235-241. doi: 10.1038/nrn2591

Roszer, T. (2017). Transcriptional control of apoptotic cell clearance by macrophage nuclear receptors. Apoptosis 22, 284-294. doi: 10.1007/s10495016-1310-x

Rothlin, C. V., Ghosh, S., Zuniga, E. I., Oldstone, M. B., and Lemke, G. (2007). TAM receptors are pleiotropic inhibitors of the innate immune response. Cell 131, 1124-1136. doi: 10.1016/j.cell.2007.10.034

Savill, J., Dransfield, I., Hogg, N., and Haslett, C. (1990). Vitronectin receptormediated phagocytosis of cells undergoing apoptosis. Nature 343, 170-173. doi: 10.1038/343170a0

Savill, J., Hogg, N., Ren, Y., and Haslett, C. (1992). Thrombospondin cooperates with CD36 and the vitronectin receptor in macrophage recognition of neutrophils undergoing apoptosis. J. Clin. Invest. 90, 1513-1522. doi: 10.1172/ JCI116019

Schrijvers, D. M., De Meyer, G. R., Kockx, M. M., Herman, A. G., and Martinet, W. (2005). Phagocytosis of apoptotic cells by macrophages is impaired in atherosclerosis. Arterioscler. Thromb. Vasc. Biol. 25, 1256-1261. doi: 10.1161/ 01.ATV.0000166517.18801.a7

Seneviratne, A., Han, Y., Wong, E., Walter, E. R. H., Jiang, L., Cave, L., et al. (2020). Hematoma Resolution In Vivo Is Directed by Activating Transcription Factor 1. Circ. Res. 127, 928-944. doi: 10.1161/CIRCRESAHA.119.315528

Shafit-Zagardo, B., Gruber, R. C., and DuBois, J. C. (2018). The role of TAM family receptors and ligands in the nervous system: from development to pathobiology. Pharmacol. Ther. 188, 97-117. doi: 10.1016/j.pharmthera.2018. 03.002

Shi, X., Luo, L., Wang, J., Shen, H., Li, Y., Mamtilahun, M., et al. (2021). Stroke subtype-dependent synapse elimination by reactive gliosis in mice. Nat. Commun. 12:6943. doi: 10.1038/s41467-021-27248-x

Sierra, A., Encinas, J. M., Deudero, J. J., Chancey, J. H., Enikolopov, G., verstreetWadiche, L. S. O., et al. (2010). Microglia shape adult hippocampal neurogenesis through apoptosis-coupled phagocytosis. Cell Stem Cell 7, 483-495. doi: 10. 1016/j.stem.2010.08.014

Silverstein, R. L., and Febbraio, M. (2009). CD36, a scavenger receptor involved in immunity, metabolism, angiogenesis, and behavior. Sci. Signal. 2:re3. doi: 10.1126/scisignal.272re3

Sisirak, V., Sally, B., D’Agati, V., Martinez-Ortiz, W., Ozcakar, Z. B., David, J., et al. (2016). Digestion of Chromatin in Apoptotic Cell Microparticles Prevents Autoimmunity. Cell 166, 88-101. doi: 10.1016/j.cell.2016.05.034

Sivandzade, F., Prasad, S., Bhalerao, A., and Cucullo, L. (2019). NRF2 and NF$\mathrm{B}$ interplay in cerebrovascular and neurodegenerative disorders: molecular mechanisms and possible therapeutic approaches. Redox Biol. 21:101059. doi: 10.1016/j.redox.2018.11.017

Splettstoesser, W. D., and Schuff-Werner, P. (2002). Oxidative stress in phagocytes"the enemy within". Microsc. Res. Tech. 57, 441-455. doi: 10.1002/jemt.10098
Sun, J., Vyas, P., Mann, S., Paganini-Hill, A., Nunes, A. C. F., Lau, W. L., et al. (2021). Insights Into the Mechanisms of Brain Endothelial Erythrophagocytosis. Front. Cell Dev. Biol. 9:672009. doi: 10.3389/fcell.2021. 672009

Szanto, A., Balint, B. L., Nagy, Z. S., Barta, E., Dezso, B., Pap, A., et al. (2010). STAT6 transcription factor is a facilitator of the nuclear receptor PPAR $\gamma$-regulated gene expression in macrophages and dendritic cells. Immunity 33, 699-712. doi: 10.1016/j.immuni.2010.11.009

Tao, C., Keep, R. F., Xi, G., and Hua, Y. (2020). CD47 Blocking Antibody Accelerates Hematoma Clearance After Intracerebral Hemorrhage in Aged Rats. Transl. Stroke Res. 11, 541-551. doi: 10.1007/s12975-019-00745-4

Ting, S. M., Zhao, X., Sun, G., Obertas, L., Ricote, M., and Aronowski, J. (2020). Brain Cleanup as a Potential Target for Poststroke Recovery: the Role of RXR (Retinoic X Receptor) in Phagocytes. Stroke 51, 958-966. doi: 10.1161/ strokeaha.119.027315

Tondo, G., Perani, D., Comi, C., and Receptor Pathways, T. A. M. (2019). at the Crossroads of Neuroinflammation and Neurodegeneration. Dis. Markers 2019:2387614.

Tong, L. S., Shao, A. W., Ou, Y. B., Guo, Z. N., Manaenko, A., Dixon, B. J., et al. (2017). Recombinant Gas6 augments Axl and facilitates immune restoration in an intracerebral hemorrhage mouse model. J. Cereb. Blood Flow Metab. 37, 1971-1981. doi: 10.1177/0271678X16658490

Trahtemberg, U., and Mevorach, D. (2017). Apoptotic Cells Induced Signaling for Immune Homeostasis in Macrophages and Dendritic Cells. Front. Immunol. 8:1356. doi: 10.3389/fimmu.2017.01356

Urday, S., Kimberly, W. T., Beslow, L. A., Vortmeyer, A. O., Selim, M. H., Rosand, J., et al. (2015). Targeting secondary injury in intracerebral haemorrhageperihaematomal oedema. Nat. Rev. Neurol. 11, 111-122. doi: 10.1038/nrneurol. 2014.264

Vaibhav, K., Braun, M., Khan, M. B., Fatima, S., Saad, N., Shankar, A., et al. (2018). Remote ischemic post-conditioning promotes hematoma resolution via AMPK-dependent immune regulation. J. Exp. Med. 215, 2636-2654. doi: 10.1084/jem.20171905

van-Charvet, L. Y., Pagler, T. A., Seimon, T. A., Thorp, E., Welch, C. L., Witztum, J. L., et al. (2010). ABCA1 and ABCG1 protect against oxidative stress-induced macrophage apoptosis during efferocytosis. Circ. Res. 106, 1861-1869. doi: 10. 1161/CIRCRESAHA.110.217281

Vernon, P. J., and Tang, D. (2013). Eat-me: autophagy, phagocytosis, and reactive oxygen species signaling. Antioxid. Redox Signal. 18, 677-691. doi: 10.1089/ars. 2012.4810

Virag, L., Jaen, R. I., Regdon, Z., Bosca, L., and Prieto, P. (2019). Self-defense of macrophages against oxidative injury: fighting for their own survival. Redox Biol. 26:101261. doi: 10.1016/j.redox.2019.101261

Wagner, K. R., Xi, G., Hua, Y., Kleinholz, M., de Courten-Myers, G. M., Myers, R. E., et al. (1996). Lobar intracerebral hemorrhage model in pigs: rapid edema development in perihematomal white matter. Stroke 27, 490-497. doi: 10.1161/ 01.str.27.3.490

Wan, X., Huo, Y., Johns, M., Piper, E., Mason, J. C., Carling, D., et al. (2013). 5'AMP-activated protein kinase-activating transcription factor 1 cascade modulates human monocyte-derived macrophages to atheroprotective functions in response to heme or metformin. Arterioscler. Thromb. Vasc. Biol. 33, 2470-2480. doi: 10.1161/ATVBAHA.113.300986

Wang, J., Fields, J., Zhao, C., Langer, J., Thimmulappa, R. K., Kensler, T. W., et al. (2007). Role of Nrf2 in protection against intracerebral hemorrhage injury in mice. Free Radic. Biol. Med. 43, 408-414. doi: 10.1016/j.freeradbiomed.2007.04. 020

Wang, S., Zhou, Y., Yang, B., Li, L., Yu, S., Chen, Y., et al. (2016). C1q/Tumor Necrosis Factor-Related Protein-3 Attenuates Brain Injury after Intracerebral Hemorrhage via AMPK-Dependent Pathway in Rat. Front. Cell Neurosci. 10:237. doi: 10.3389/fncel.2016.00237

Wang, Y. J., Huang, Y., Xu, Y. Z., Ruan, W. C., Wang, H. J., Zhang, Y. H., et al. (2018). AMPK/Nrf2 Activator Reduces Brain Inflammation After Stroke by Enhancing Microglia M2 Polarization. Antioxid. Redox Signal. 28, 141-163.

Wang, Y., Chen, Q., Tan, Q., Feng, Z., He, Z., Tang, J., et al. (2018). Simvastatin accelerates hematoma resolution after intracerebral hemorrhage in a PPARgamma-dependent manner. Neuropharmacology 128, 244-254. doi: 10.1016/j.neuropharm.2017.10.021 
Werneburg, S., Jung, J., Kunjamma, R. B., Ha, S. K., Luciano, N. J., Willis, C. M., et al. (2020). Targeted Complement Inhibition at Synapses Prevents Microglial Synaptic Engulfment and Synapse Loss in Demyelinating Disease. Immunity 52, 167-182e7. doi: 10.1016/j.immuni.2019.12.004

Winn, N. C., Volk, K. M., and Hasty, A. H. (2020). Regulation of tissue iron homeostasis: the macrophage "ferrostat". JCI Insight 5:e132964. doi: 10.1172/ jci.insight.132964

Woo, M. S., Yang, J., Beltran, C., and Cho, S. (2016). Cell Surface CD36 Protein in Monocyte/Macrophage Contributes to Phagocytosis during the Resolution Phase of Ischemic Stroke in Mice. J. Biol. Chem. 291, 23654-23661. doi: 10.1074/ jbc.M116.750018

Wu, H. J., Zheng, J. W., Xu, S. B., Fang, Y. J., Wu, Y. X., Zeng, J. X., et al. (2021). Mer regulates microglial/macrophage M1/M2 polarization and alleviates neuroinflammation following traumatic brain injury. J. Neuroinflamm. 18:20. doi: 10.1186/s12974-020-02041-7

Wu, J., Hua, Y., Keep, R. F., Nakamura, T., Hoff, J. T., and Xi, G. (2003). Iron and iron-handling proteins in the brain after intracerebral hemorrhage. Stroke 34, 2964-2969. doi: 10.1161/01.STR.0000103140.52838.45

Wu, Y., Tang, K., Huang, R. Q., Zhuang, Z., Cheng, H. L., Yin, H. X., et al. (2011). Therapeutic potential of peroxisome proliferator-activated receptor gamma agonist rosiglitazone in cerebral vasospasm after a rat experimental subarachnoid hemorrhage model. J. Neurol. Sci. 305, 85-91. doi: 10.1016/j.jns. 2011.03.006

Xi, G., Keep, R. F., and Hoff, J. T. (2006). Mechanisms of brain injury after intracerebral haemorrhage. Lancet Neurol. 5, 53-63. doi: 10.1016/S14744422(05)70283-0

Xiong, X. Y., Wang, J., Qian, Z. M., and Yang, Q. W. (2014). Iron and intracerebral hemorrhage: from mechanism to translation. Transl. Stroke Res. 5, 429-441. doi: 10.1007/s12975-013-0317-7

Xu, J., Chen, Z., Yu, F., Liu, H., Ma, C., Xie, D., et al. (2020). IL-4/STAT6 signaling facilitates innate hematoma resolution and neurological recovery after hemorrhagic stroke in mice. Proc. Natl. Acad. Sci. U. S. A. 117, 32679-32690. doi: $10.1073 /$ pnas.2018497117

Xue, M., and Yong, V. W. (2020). Neuroinflammation in intracerebral haemorrhage: immunotherapies with potential for translation. Lancet Neurol. 19, 1023-1032. doi: 10.1016/S1474-4422(20)30364-1

Youssef, L. A., Rebbaa, A., Pampou, S., Weisberg, S. P., Stockwell, B. R., Hod, E. A., et al. (2018). Increased erythrophagocytosis induces ferroptosis in red pulp macrophages in a mouse model of transfusion. Blood 131, 2581-2593. doi: 10.1182/blood-2017-12-822619

Yurdagul, A., Subramanian, M., Wang, X. B., Crown, S. B., Ilkayeva, O. R., Darville, L., et al. (2020). Macrophage Metabolism of Apoptotic Cell-Derived Arginine Promotes Continual Efferocytosis and Resolution of Injury. Cell Metab. 31, 518-533.e10. doi: 10.1016/j.cmet.2020.01.001

Zagorska, A., Traves, P. G., Lew, E. D., Dransfield, I., and Lemke, G. (2014). Diversification of TAM receptor tyrosine kinase function. Nat. Immunol. 15, 920-928. doi: 10.1038/ni.2986

Zarruk, J. G., Greenhalgh, A. D., and David, S. (2018). Microglia and macrophages differ in their inflammatory profile after permanent brain ischemia. Exp. Neurol. 301, 120-132. doi: 10.1016/j.expneurol.2017.08.011

Zhang, H., Li, F., Yang, Y., Chen, J., and Hu, X. (2015). SIRP/CD47 signaling in neurological disorders. Brain Res. 1623, 74-80. doi: 10.1016/j.brainres.2015.03. 012

Zhang, W., Zhao, J., Wang, R., Jiang, M., Ye, Q., Smith, A. D., et al. (2019). Macrophages reprogram after ischemic stroke and promote efferocytosis and inflammation resolution in the mouse brain. CNS Neurosci. Ther. 25, 13291342. doi: $10.1111 / \mathrm{cns} .13256$

Zhao, B., Sun, L. K., Jiang, X., Zhang, Y., Kang, J., Meng, H., et al. (2019). Genipin protects against cerebral ischemia-reperfusion injury by regulating the UCP2SIRT3 signaling pathway. Eur. J. Pharmacol. 845, 56-64. doi: 10.1016/j.ejphar. 2018.12.028

Zhao, J. L., Chen, Y. J., Yu, J., Du, Z. Y., Yuan, Q., Sun, Y. R., et al. (2020). ISO-alpha-acids improve the hematoma resolution and prevent peri-hematoma inflammations by transforming microglia via PPARgamma-CD36 axis in ICH rats. Int. Immunopharmacol. 83:106396. doi: 10.1016/j.intimp.2020.10 6396
Zhao, X., Sun, G., Ting, S. M., Song, S., Zhang, J., Edwards, N. J., et al. (2015a). Cleaning up after ICH: the role of $\mathrm{Nrf} 2$ in modulating microglia function and hematoma clearance. J. Neurochem. 133, 144-152. doi: 10.1111/jnc.12974

Zhao, X. R., Gonzales, N., and Aronowski, J. (2015c). Pleiotropic role of PPARgamma in intracerebral hemorrhage: an intricate system involving Nrf2, RXR, and NF-kappaB. CNS Neurosci. Ther. 21, 357-366. doi: 10.1111/cns. 12350

Zhao, X., Sun, G., Zhang, J., Ting, S. M., Gonzales, N., and Aronowski, J. (2015b). Dimethyl Fumarate Protects Brain From Damage Produced by Intracerebral Hemorrhage by Mechanism Involving Nrf2. Stroke 46, 1923-1928. doi: 10.1161/ STROKEAHA.115.009398

Zhao, X. R., Grotta, J., Gonzales, N., and Aronowski, J. (2009). Hematoma Resolution as a Therapeutic Target The Role of Microglia/Macrophages. Stroke 40, S92-S94. doi: 10.1161/STROKEAHA.108.533158

Zhao, X., and Aronowski, J. (2013). Nrf2 to pre-condition the brain against injury caused by products of hemolysis after ICH. Transl. Stroke Res. 4, 71-75. doi: 10.1007/s12975-012-0245-y

Zhao, X., Kruzel, M., Ting, S. M., Sun, G., Savitz, S. I., and Aronowski, J. (2021). Optimized lactoferrin as a highly promising treatment for intracerebral hemorrhage: pre-clinical experience. J. Cereb. Blood Flow Metab. 41, 53-66. doi: 10.1177/0271678X20925667

Zhao, X., Sun, G., Zhang, J., Strong, R., Song, W., Gonzales, N., et al. (2007b). Hematoma resolution as a target for intracerebral hemorrhage treatment: role for peroxisome proliferator-activated receptor gamma in microglia/macrophages. Ann. Neurol. 61, 352-362. doi: 10.1002/ana.21097

Zhao, X., Sun, G., Zhang, J., Strong, R., Dash, P. K., Kan, Y. W., et al. (2007a). Transcription factor Nrf2 protects the brain from damage produced by intracerebral hemorrhage. Stroke 38, 3280-3286. doi: 10.1161/STROKEAHA. 107.486506

Zheng, J., Sun, Z., Liang, F., Xu, W., Lu, J., Shi, L., et al. (2019). AdipoRon Attenuates Neuroinflammation After Intracerebral Hemorrhage Through AdipoR1-AMPK Pathway. Neuroscience 412, 116-130. doi: 10.1016/ j.neuroscience.2019.05.060

Zhou, X., Xie, Q., Xi, G., Keep, R. F., and Hua, Y. (2014). Brain CD47 expression in a swine model of intracerebral hemorrhage. Brain Res. 1574, 70-76. doi: 10.1016/j.brainres.2014.06.003

Zhou, Y., Wang, Y., Wang, J., Anne Stetler, R., and Yang, Q. W. (2014). Inflammation in intracerebral hemorrhage: from mechanisms to clinical translation. Prog. Neurobiol. 115, 25-44. doi: 10.1016/j.pneurobio.2013.11.003

Zhuang, J., Peng, Y., Gu, C., Chen, H., Lin, Z., Zhou, H., et al. (2020). Hematoma Clearance and Improves Neurological Outcome via the PPAR-gamma Pathway After Intracerebral Hemorrhage. Transl. Stroke Res. 12, 660-675. doi: 10.1007/ s12975-020-00842-9

Zia, E., Melander, O., Bjorkbacka, H., Hedblad, B., and Engstrom, G. (2012). Total and differential leucocyte counts in relation to incidence of stroke subtypes and mortality: a prospective cohort study. J. Intern. Med. 272, 298-304. doi: 10.1111/j.1365-2796.2012.02526.x

Ziai, W. C. (2013). Hematology and inflammatory signaling of intracerebral hemorrhage. Stroke 44, S74-S78. doi: 10.1161/STROKEAHA.111.000662

Conflict of Interest: The authors declare that the research was conducted in the absence of any commercial or financial relationships that could be construed as a potential conflict of interest.

Publisher's Note: All claims expressed in this article are solely those of the authors and do not necessarily represent those of their affiliated organizations, or those of the publisher, the editors and the reviewers. Any product that may be evaluated in this article, or claim that may be made by its manufacturer, is not guaranteed or endorsed by the publisher.

Copyright (C) $2022 \mathrm{Liu}, \mathrm{Zhu}$ and Leung. This is an open-access article distributed under the terms of the Creative Commons Attribution License (CC BY). The use, distribution or reproduction in other forums is permitted, provided the original author(s) and the copyright owner(s) are credited and that the original publication in this journal is cited, in accordance with accepted academic practice. No use, distribution or reproduction is permitted which does not comply with these terms. 